\title{
Life satisfaction, income comparisons and personality traits
}

\author{
Santi Budria \\ Universidad Pontificia Comillas \\ Center of Applied Economics Studies of the Atlantic (CEEApIA) \\ Institute of Labor Economics (IZA) \\ and \\ Ada Ferrer-I-Carbonell \\ Institut d'Anàlisi Econòmica (IAE-CSIC) and Barcelona GSE
}

June 2016

\begin{abstract}
People gain utility from occupying a higher ranked position in the income distribution of the reference group. This paper investigates whether these gains depend on an individual's set of personality traits. Using the 2000 to 2013 waves of the German Socio-economic Panel dataset (SOEP), a subjective question on Life Satisfaction, and three different sets of personality indicators, we find significant and robust differences across groups and conclude that personality determines individuals' rank sensitiveness. The heterogeneity on the importance of income comparisons is relevant, for example, when building economic models, predicting individuals' behavior, or making welfare judgments.
\end{abstract}

Keywords: Life satisfaction; income comparisons; personality traits.

PsycINFO classification: 2900; 3120

JEL codes: D62; I31 


\section{Introduction}

Individuals are rank sensitive: they care about how well they perform in comparison with the relevant others. In economics and other disciplines, there has been an important set of literature devoted to understanding how individuals are influenced by their reference group and who their reference group is. Over the last two decades, the distinction between absolute and relative formulations of utility has proven a useful concept to rationalize a large set of unexplained phenomena in a variety of fields, including asset pricing, growth, consumption behavior and wealth inequality (for a survey, Thimme, 2016). Advances at the theoretical level have been parallel to a new wave of empirical papers assessing the relative importance of relative effects for individuals' utility or welfare. Some of these empirical papers are based on the use of self-reported happiness or life satisfaction as a proxy for individual utility. The empirical evidence seems clear: people gain utility from occupying a higher ranked position in the income distribution of the reference group (Brown et al., 2008; Clark et al., 2009a; Powdthavee, 2009; Boyce, 2010).

This paper examines whether the rank effect differs between individuals endowed with different personality traits. The interaction between personality and social comparisons remains mostly unexplored in the happiness literature. This is somewhat surprising, insofar as evidence from other fields suggests that personality influences attention and sensitiveness to social information. Social psychologists have long recognized that the degree of competition between commensurate rivals and the costs of ranking low depend on an individual's personality (Beach and Tesser, 2000; Garcia et al., 2005). The response to hedonically relevant information, including social comparisons, typically depends on specific personality traits such as self-esteem, optimism, neuroticism, and extraversion (Wheeler and Miyake, 1992; Aspinwall and Taylor, 1993). Further investigations have shown that optimistic and emotional stable individuals tend to be less reactive than other individuals to external stimuli and comparison information (Larsen and Ketelaar, 1991; Derryberry and Reed, 1994; Lyubomirsky and Ross, 1997; and Lyubomirsky et al., 2001). In this paper, we ask whether the mediating role of personality extends to the realm of income 
comparisons and life satisfaction. Under the light of the evidence from psychology research, we hypothesize that this is the case. In addition, we have empirical evidence pointing at the relevance of personality on defining the importance of income for life satisfaction (Boyce and Wood, 2011, Proto and Rustichini, 2011).

The results are based on the 2000-2013 waves of the German Socio-Economic Panel dataset (SOEP) and three different sets of personality measures: (i) the Big Five Inventory (BFI), a widely accepted approach to conceptualizing personality; (ii) the degree of individuals' external Locus of Control, i.e., the extent to which respondents feel they are not in command of their life; and (iii) a measure on individual's positive and negative reciprocity, an important concept in social psychology capturing how individuals respond to other individuals' actions. A feature of our analysis is that each individual's personality is recorded more than once: personality measures, first introduced in 2005, were asked again in the 2009, 2013 (BFI) and 2010 (LOC, reciprocity) waves of the SOEP. This allows us extract a time invariant component of personality that is free from personality-changing life events. In our analysis, the dependent variable is a subjective measure of life satisfaction, which can be regarded as a proxy for individual utility.

In economics, the use of explicit personality measures has increased over the last recent years. There is growing evidence on the relationships between personality and a variety of life outcomes, including health (Hampson et al., 2006), test performance (Heckman et al., 2014), and economic success (for a survey, Almlund et al., 2011). Similarly, there is evidence that personality affects a wide range of labor market outcomes such as occupational choices and job search effort (Caliendo et al., 2014a,b), employment (Mohanty, 2010, Uysal and Pohlmeier, 2011) and earnings (Mueller and Plug, 2006, Semykina and Linz, 2007, and Heineck and Anger, 2010). These effects have led researchers to argue that personality should be given greater consideration in economics (Borghans et al., 2008). Examining the role of personality in shaping individual preferences over the rank they occupy within the income distribution of their 
reference group is consistent with this interest, to the extent that rank sensitiveness shapes individual behavior in several domains. Income and consumption externalities have important implications for a variety of policy relevant issues at the micro and macro level, including optimal taxation, public redistribution, and the welfare costs of aggregate fluctuations (Frey and Stutzer, 2002; Di Tella et al., 2003; Senik, 2005; and Clark et al., 2008a). In addition, these externalities are part of individuals' welfare and preferences and thus influence human behaviour. Its understanding will therefore contribute to, for example, estimate the impact of policy changes on individuals' welfare or predict individuals' behavioural responses to changes in the markets.

The happiness literature does argue that individuals' personality is the most important component of individual heterogeneity in happiness equations (Boyce, 2010). Consistent with this view, researchers in the field have acknowledged the importance of controlling for this individual heterogeneity when estimating life satisfaction equations (Ferrer-i-Carbonell and Frijters, 2004). This paper forms part of the emerging interest on personality data by providing empirical evidence on the importance of personality in forming individuals' sensitiveness to others' income. The empirical results reveal a significant heterogeneity. This is, the effect on life satisfaction of the rank (position) that individuals occupy within the income distribution of their reference group varies across personality groups. Individuals at the top of the distribution of extraversion, conscientiousness, external locus of control and negative reciprocity are more sensitive to their income rank than the ones at the bottom; while the opposite is true for those on the top of the distribution of openness to experiences and positive reciprocity.

The paper is organized as follows: Section 2 discusses the literature; section 3 presents the data, and the satisfaction and the personality measures used in this paper; section 4 outlines the empirical approach and hypothesis; section 5 presents the results; and section 6 presents the concluding remarks.

\section{Previous literature}


The income rank hypothesis states that people gain utility from occupying a higher rank in the income distribution of their reference group. The empirical evidence using self-reported satisfaction data suggests that individuals are indeed rank sensitive. Clark et al. (2009a) match individual economic satisfaction scores from eight years (panel data) of the Danish European Community Household Panel (ECHP) with administrative data to calculate individuals' income and to estimate the income distribution of their neighborhood. They find evidence that individual reported financial satisfaction positively depends on the income rank that the households occupies in the neighborhood. Specifically, a 1decile increase in the income rank is as important in terms of financial satisfaction as an income increase by a factor of almost 5. Based on Indonesian cross-section data from the year 2000, Powdthavee (2009) provides very similar estimates when using respondents' perception on own relative economic position as dependent variable. Brown et al. (2008) use cross-section data for the UK for 1998 and find evidence of a positive effect of a worker's rank within the workplace earnings distribution on self-reported satisfaction in different job related domains.

Previously to the above mentioned results, researchers using life-satisfaction questions as a proxy measure for utility empirically examined the relative income hypothesis by using the mean income level of the reference group rather than the rank. These studies found a negative (and statistically significant) effect of the reference group mean income on self-reported satisfaction (Blanchflower and Oswald, 2004; Ferrer-i-Carbonell, 2005; Luttmer, 2005; Senik，2009). The robustness of this effect is remarkable except for a few idiosyncratic exceptions. Senik (2004) finds a positive effect of the mean income of the reference group on happiness for Russia during the 1994-2000 transition period. Senik's explanation for this finding is based on Hirschmann's (1973) tunnel effect: she argues that when living under large levels of economic uncertainty, individuals may interpret a high income of the reference group as a good signal about own future prospects. In short, during this period in Russia, the negative effect through comparison status may have been more than offset by the positive effect related to the information that higher incomes carry. A similar result is 
reported in Caporale et al. (2009) for Eastern European countries and in Clark et al. (2009b) for job (not life) satisfaction data when using co-workers as the comparison group.

Boyce et al. (2010a) use data from the British Household Panel Survey to test for relative income effects using both, the average income of the reference group and the rank. These authors find evidence in favour of the income rank as a better indicator of relative income and in this paper we therefore use the later.

\subsection{Personality, social comparisons and economic outcomes}

The existing empirical estimates of the effect that income comparisons exert on life satisfaction have been estimated for the average respondent with the exception of two papers examining the life-cycle patterns of income comparisons (Akay and Martinsson, 2012; FitzRoy et al., 2014). Up to date the only existing empirical evidence on the interplay between personality and social comparisons is based on laboratory experiments in psychology. Although these papers do not offer a direct test of the role of personality on shaping individuals' preferences, they do provide some indirect evidence. It is well accepted in the literature that the response to social comparisons typically depends on personality (Wheeler and Miyake, 1992, Aspinwall and Taylor, 1993). For instance, the extent and consequences of social comparisons is found to differ between those individuals with a predisposition to be happy or unhappy. In general, individuals with a positive predisposition think more positively about themselves, feel more personal control, react more intensely to positive events and life outcomes, and show shorter drops in response to unfavourable life events (Seidlitz et al., 1997, Lyubomirsky and Tucker, 1998). Individuals with a negative predisposition are hurt when the comparisons information is unfavorable, but non-reactive when it is favorable. On the contrary, positive individuals do not appear to be hurt by unfavorable social information (Lyubomirsky and Ross, 1997, and Lyubomirsky et al., 2001).

Laboratory experiments have also shown that optimistic and non-depressive people can cope by reducing social comparisons when performing poorly 
(Gibbons et al. 1994), while depressed people increase social comparisons when performing poorly (Swallow and Kuiper, 1992). Similarly, neurotic people are more reactive than stable individuals to external stimuli and are more likely to experience unpleasant affect when exposed to a negative stimulus (Larsen and Ketelaar 1991). Moreover, extraverts have an above-average sensitivity to reward stimuli (Derryberry and Reed, 1994).

How and to what extent these effects extend to the realm of income comparisons remains unexplored. It is therefore very difficult to lucubrate how the different personality traits examined in this paper mediate in the rank-life satisfaction relationship. The evidence on the potential implications of the different personality traits is very sketchy an incomplete. The psychological literature argues that neuroticism is linked to higher sensitivity to negative emotions like anger, hostility or depression (Clark and Watson, 2008), and modern studies identify this personality trait with sensibility to negative outcomes, threats, and punishments (see DeYoung et al., 2010, for a survey). Therefore, we may hypothesize that neuroticism enlarges the effect of rank on life satisfaction. The evidence at hand also suggests that conscientious individuals tend to value wealth accumulation (Ameriks et al., 2003), set themselves higher goals and care more about achieving them (Barrick et al., 1993; DeNeve and Cooper, 1998). Therefore, it is likely that conscientious individuals are more reactive to income comparisons. The extent to which one finds social comparisons inspiring or threatening is known in the field of psychology to depend on whether one finds a sense of control over the dimension under evaluation (Lockwood, 2002). Therefore, we hypothesize that LOC will be a relevant personality trait on defining individuals' rank sensitiveness. The available evidence for reciprocity is very scarce. Fehr and Gächter (2000) argue that positive reciprocity has powerful implications for many economic domains, including the enforcement of explicit social norms; and Dohmen et al. (2009) find that being positively reciprocal predicts higher work effort.

\section{Data and measurement}

\subsection{Data}


Initiated in 1984, the German SOEP is a wide-ranging representative longitudinal annual survey of households that contains a large set of personal, family, and

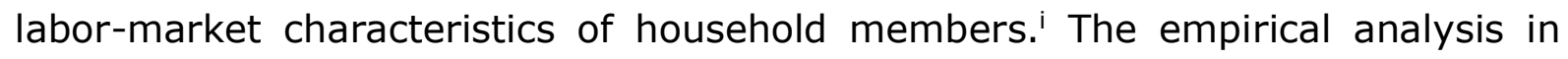
this paper is based on a fourteen-year span of this data, i.e., 2000-2013. The unit of analysis is the individual participant. Having excluded all observations with missing values in the model covariates, we retain a final sample of 223,805 observations.

To test for the importance of relative income on individuals' utility, we use a life satisfaction question. In the German SOEP, the life satisfaction question runs as follows:

- How satisfied are you with your life, all things considered?

The answer to this question takes discrete values from 0 to 10 and hereafter will be referred to as Life Satisfaction (LS). Despite a long tradition among sociologist and psychologist, subjective data was subject to criticisms among some economists concerned about the potential biases arising from cultural differences, framing problems, cognitive bias, and mood effects. For reasons of space, the present paper overlooks such discussion by simply noting that the evidence accumulated over recent years has proven the validity and consistency of self-reported data. For an overview see Ferrer-i-Carbonell (2013). In a nutshell, subjective measures of satisfaction and well-being have a predictive power over relevant actions, for example they predict future divorce (Guven et al., 2012) and job quits (Clark, 2001); and are related (in the expected direction) to a number of objective indicators including physical health and longevity (Danner et al., 2001), macroeconomic fluctuations (Di Tella et al., 2003), unemployment (Clark et al., 2008b), and to measures of revealed preferences (Oswald and $\mathrm{Wu}, 2010$ ). These life satisfaction measures also show a reasonable amount of internal consistency and temporal reliability: they correlate well with one another and with alternative methods of measurement,

\footnotetext{
i For detailed information see Wagner at al. (2007) and Frick et al. (2007).
} 
including ratings made by family and friends, facial measures of emotion, and a vast array of psychological and psychosocial indicators (Cacioppo et al., 2008).

Table 1 contains the summary statistics of the sample. The average Life Satisfaction over the sample period is 6.97 (SD =1.77). Average monthly household income amounts to 2,782 eurosii. The average age is 49.9 years and the average educational attainment is 12.2 years of schooling. Women account for $52.2 \%$ of the sample. Most individuals are employed (62.2\%) and married or live with a partner (66.2\%). In the regression stage, the continuous variables household income, age and age squared, years of completed education, number of children, and adults at home are entered in their logarithm form so as to take into account their decreasing marginal contribution to life satisfaction. In order to consider heterogeneous household size and cost-of-life adjustments, all income-based variables in the paper are transformed using the OECD equivalence scale $e^{\mathrm{iii}}$ and normalized into real terms using the yearly consumer price index.

\subsection{Personality traits}

\subsubsection{Measurement}

An important field within personality research is the development of a taxonomy that allows categorizing individuals' personality into some domains. The development of the theoretical models of personality has been accompanied by research on how to measure such theoretical constructs. There are currently a set of self-reported questions that have been developed and tested to measure different personality taxonomies. One of the most well-accepted measures within

\footnotetext{
ii Frick and Grabka (2005) stress the need for imputation due to the underlying selectivity processes of item non-response on income questions. They also warn that ignoring cases with item non-response tends to underestimate income levels and disregard observations at the both tails of the income distribution, especially at the upper end. To address these issues, we make use of the 5 alternative income imputations provided in the central SOEP's datasets. Specifically, the household income variable used in the paper is a weighted average of the 5 imputations.

iii The OECD equivalent household size, $E$ is defined as follows: let $A$ be the number of household members who are older than 14 , and let $S$ be the household size, then $E=$ $1+0.7 \times(A-1)+0.5(S-A)$.
} 
the literature is the Big 5, although other taxonomies of personality are also broadly accepted.

In 2005 the German SOEP included for the first time a set of self-reported questions designed to capture three taxonomies of personality: a short version of the Big Five Inventory (BFI), a set of items related to Locus of Control (LOC), and measures of negative and positive reciprocity norms. These personality measures were asked again in the 2009, 2013 (BFI), and 2010 (LOC, reciprocity) waves of the SOEP.

The Big Five and the LOC measures are two alternative well known ways to describe individuals' personality. LOC aims at capturing the degree to which individuals believe that the course of their life is under their control (e.g., depends on effort and ability) or depends on external circumstances, such as luck or social conditions. The BFI is a well-accepted measure to describe the five major traits that define human personality across cultures (Costa and McCrae, 1992): neuroticism, extraversion, openness-to-experiences, agreeableness, and conscientiousness. Neuroticism is the tendency to experience negative emotions such as anxiety and depression; extraversion is the tendency to be sociable, warm, active, assertive, cheerful, and in search of stimulation; openness to experience is the tendency to be imaginative, creative, unconventional, emotionally, and artistically sensitive; agreeableness reflects a dimension of interpersonal relations and is characterized by altruism, trust, modesty, and cooperativeness; and conscientiousness is the tendency to be organized, strongwilled, persistent, reliable, and a follower of rules and ethical principles. ${ }^{\text {iv }}$

There are different self-reported inventories to measure the Big Five model. The Big Five Inventory (BFI), for example, consists of 44 self-report items while the NEO personality inventory consists of 60 items. The BFI questionnaire used in the German SOEP is a short version of the BFI known as the BFI-S that consists of 15 items ( 3 for each personality dimension). Short versions of the BFI are

\footnotetext{
iv For a detailed discussion on the origin, measurement and conceptualization of the Big Five and, more generally, personality constructs, see Borghans et al. (2008).
} 
typically used in large-scale household questionnaires, as time is an important constraint. A detailed description of the short version used in the questionnaire we use in the paper can be found in Lang et al. (2011). Despite psychologists typically work with longer questionnaires, the shortened version used in this paper has been validated against longer inventories. Using multiple samples and for two languages, English and German, Rammstedt and John (2007) conclude that, despite some losses in comparison to the full-scale, a short BFI questionnaire can exhibit acceptable psychometric properties. Lang et al. (2011) also show that the short BFI questionnaire can replicate a five-factor structure in face-to-face as well as self-administrative questionnaires. Hahn et al. (2012) examine the degree to which this brief measure capture the intended constructs as assessed by longer, more differentiated and robust questionnaires. Their results show convergent as well as discriminant validity of the BFI-S scales with the NEO-PIR dimensions and facets, confirming previous findings by Herzberg and Brähler (2006). They also find acceptable levels of internal consistency and stability over a period of 18 months.

The 15 BFI-S items used in the questionnaire as well as the construction of the personality measures used in the paper are described in the Appendix. All personality measures used in the paper can take values from 1 to 7 . An important issue in personality measures is the concern that variability in the resulting scores might arise from measurement error. In our data, encompassing tests of internal consistency were satisfactory. ${ }^{\vee}$

\footnotetext{
$\checkmark$ Factor analyses clearly replicated the Big Five factors by yielding a correlation matrix with five eigenvalues above unity. The five principal components accounted for $60.7 \%$ of the total variance. The Cronbach's alphas for the five dimensions were $0.659,0.621,0.618,0.596$ and 0.502 . In their detailed test of validity of the BFI-S, Hahn et al. (2012) report similar coefficients and regard them as satisfactory, despite shortcomings for agreeableness. It must be noticed that for a given level of internal consistency, fewer items per dimension result into lower alphas (Mueller and Plug, 2006). Hence, although these reliability coefficients are towards the lower range of admissible values, they point to a reasonable amount of internal consistency given the low (3) number of items per personality traits.
} 
Locus of Control (LOC), a model developed by Rotter (1966), is the degree to which individuals feel the control of their life is on their own hands (internal) or depends on external factors (external). People with a high score in the items measuring external LOC believe that fate, luck, social conditions, or any other external circumstances are important determinants of the course of their lives; while those with a high score on internal LOC perceive that their life depends on own ability and effort.

In the SOEP data, LOC is surveyed with 10 items. Other papers using this measure are Caliendo et al. (2015) and Piatek and Pinger (2015). In our data internal LOC was found to exhibit a very limited amount of construct validity ${ }^{\mathrm{vi}}$, which means that the surveyed items are not appropriate for measuring the underlying scale and we therefore excluded this measure from the analyses. In the paper we focus exclusively on the external LOC items. These are described in the Appendix.

Our last measure of personality is reciprocity, which is computed by six items of which three refer to cooperative tendencies ("positive reciprocity") and the other three to retaliatory aspects ("negative reciprocity"). The positive and negative reciprocity items relate to an important concept in social psychology aimed at measuring individuals negative and positive responses to other individuals' actions. Despite the reduced number of items, the internal consistency of these two constructs is remarkably large. vii

Table 2 shows the sample averages for each of the eight personality measures used in the paper. In the regression stage, each personality trait is normalized to an average of zero and a standard deviation of 1 . Figure 1 shows the frequency distribution of the normalized values.

\footnotetext{
vi The alpha reliability coefficient was below 0.20.

vii The Cronbach's alphas for the two dimensions were 0.623 and 0.824 , respectively. Auxiliary factor analysis supported the existence of two orthogonal factors, thus validating the a priori distinction between positive and negative reciprocity.
} 


\subsubsection{The stability of personality traits}

Since an individual's personality is measured three times in our panel (2005, 2009/2010, 2013), we use this information to construct an individual timeinvariant score for each personality trait. This is, if personality traits were to change over the life-cycle, we extract from the data that part that is time constant and exclude the yearly variation. This yearly variation can be caused, among others, by true personality changes or measurement errors. Although there is a large debate in the personality literature, there seems to be consensus among researchers on that personality is enduring and that changes after adulthood are smaller than at younger ages (Roberts and Del Vecchio, 2000; Costa and McCrae, 2002, 2006). Nevertheless, the size and importance of adulthood personality changes are at debate. While some argue that changes are modest, others defend that changes are significant until age 40 (Roberts, et al., 2006). There is agreement however on that these changes decrease with age. Most relevant for the subjective well-being literature is the issue on the determinants of these personality changes. Current findings points to changes in personality due to a maturity process (Roberts et al., 2001) rather than to the environment. In other words, personality changes might be, to a large extent, systematically related to age. For example, individuals become less neurotic and more agreeable and conscientious as time goes by (Soto et al., 2011, Kandler et al., 2012). In terms of the life-satisfaction literature this means that personality changes might not be strongly correlated with any life event (other than age) that could correlate with happiness as well. McGuee et al. (1993), quoted in Borghans et al. (2008), argue that "environmental factors do not exert cumulative long-lasting influences [...] even when substantial, environmental factors do not normally lead, in adulthood, to a long-term redirection to the individual course of personality development" (pp. 105-106).

The study by Cobb-Clark and Schurer (2012) is particularly relevant in this context. They systematically and accurately analyze individual personality changes in a four year period. To this end, they use the HILDA, an Australian household panel dataset similar to the one used here that includes the Big Five Inventory. These authors conclude that individual changes are not only small but 
also generally unrelated to experiencing adverse life events, such as family related events (death of a spouse, child, relative, or friend or being a victim of property crime), employment and income changes (worsening of finances, retiring, being fired or being unemployed), and health related shocks (serious illness or injury, physical violence, or new health conditions). A relevant article in the context of the present paper is Boyce et al. (2013). The paper does not focus on the determinants of personality changes over time but it examines how these changes correlate with life satisfaction. Although the authors find a correlation between personality changes and life-satisfaction, we cannot rule out that these are due to aging, as the regressions use individuals fixed effects and can thus not control for age.

In this paper we do not focus on explaining personality changes over time or how these affect life-satisfaction. Nevertheless, and if we are at examining the exogenous relationship between rank sensitiveness and personality, we need to take into account that personality might change over time. Thus, and although the mean age of the respondents in our sample is 49.9 years, and therefore any interplay between early life events and personality is likely to be insignificant, the empirical approach used in the paper aims at reconciling these different views in the literature. Since we have personality measured at three different moments in time, we can regress each personality trait on a fourth order polynomial in age and an individual fixed effect. The personality measure used in the paper is the (normalized) estimated individual fixed effect of this regression. This measure is time constant and, at the same time, free from ageing. In alternative specifications, we included more explanatory variables in the personality regression (e.g., labor-market status, marital condition income, health and region), which lead to very similar regression results.

\section{Empirical approach}

\subsection{Definition of reference group}

The literature on reference group formation does not yet provide much empirical evidence or theoretical insights on how individuals form their reference group and what is the stability of those across time and domains. On one side, large- 
scale surveys do not contain direct questions about the composition of the reference groups and empirical results from pilot surveys or experimental evidence (see for example Clark and Senik, 2010) are not yet directly applicable to large questionnaires. The empirical literature has diverged on the operationalization and identification of the reference group, although the studies can be clustered into two: those assuming that comparisons take place among people living in the same geographical area; and those defending that individuals' reference group is formed by those who are similar to them (e.g., same age or socio-economic status). In the first group, we find a large variety in the level of aggregation, ranging from countries (Di Tella and MacCulloch, 2003), American states (Blanchflower and Oswald, 2004), Public Use Microdata Areas in the US (Luttmer, 2005), census tracks in Canada (Helliwell and Huang, 2010) to neighbourhoods (Clark et al., 2009a; Dittmann and Goebel, 2010) and subdistricts (Powdthavee, 2009). Similarly, the variables defining the reference group in the second group of studies differ largely: while some authors consider that comparisons take place only between those in the same cohort (McBride, 2001), others include a larger set of individual characteristics (Senik, 2004; Ferrer-i-Carbonell, 2005) or include those with similar wage determinants when it comes to satisfaction with the job (Brown at al., 2008; Clark et al., 2009b). Although there is some research on the endogeneity of the reference group formation (Falk and Knell, 2004; Senik, 2009; Clark and Senik, 2010), the evidence is still very scarce.

This paper follows a mixed approach by constructing reference groups taking into account some individual characteristics as well as introducing a geographical dimension into the analysis. In concrete, we generate reference groups by partitioning the sample into various groups using the geographical region where the household lives (West or East Germany), the gender of the respondent, the education attainment of the respondent (less than 10,10-10.5, 11-11.5, 12, and more than 12 years of schooling), and the age of the respondent (younger than $25,25-34,35-44,45-64$, and older than 64). The combination of these criteria produces 100 different groups. Although sensitive analysis showed that it did not affect our results, we dropped those individuals in a group with less than 10 
observations in a given year. In total 395 observations were dropped from the sample.

While the reference group is defined at the individual level, the reference income is taken at the household level. Individuals are assumed to obtain information about the others through their own reference group, i.e., we assume that individuals generate information by looking at those similar to them. Nevertheless, we take equivalent household (and not personal) income as the relevant measure and assume that, at least to a large extent, there is income pooling at the household level.

\subsection{Estimating procedure}

Life Satisfaction (LS) is assumed to be a function of personal characteristics and circumstances,

$$
L S=f\left(L S^{*}(X, y, r)\right)
$$

where $X$ is a vector of socio-economic characteristics, $y$ is household income, and $r$ is the individual normalized income rank. The rank is defined as the position of individual $i$ in terms of his or her household income as a proportion of the number of individuals in group $g$. This is: $\left(\mathrm{P}_{\mathrm{ig}}-1\right) /\left(\mathrm{N}_{\mathrm{g}}-1\right)$, where $\mathrm{P}_{\mathrm{ig}}$ is the position of individual $\mathrm{i}$ in group $\mathrm{g}$, and $\mathrm{N}_{\mathrm{g}}$ is the number of individuals in the group. Normalized rank is zero for the poorest individual in the group and one for the richest one.

We take reported life satisfaction to be cardinal. This is, we assume that the distance between the eleven satisfaction categories carry a meaning. It has been shown that assuming cardinality as oppose to regress satisfaction with ordinal models is rather irrelevant for the results in terms of trade-offs between explanatory variables (Ferrer-i-Carbonell and Frijters, 2004) while it has the advantage of yielding coefficients that can be directly interpreted as marginal effects. We rely on the Probit Adapted Ordinary Least Squares (POLS) as developed by Van Praag and Ferrer-i-Carbonell (2008, p. 29-34). As a robustness check, we have estimated the model with the standard linear model 
and found very small differences in terms of trade-offs between variables and statistical significance. The POLS model has been applied in the happiness literature by Stevenson and Wolfers (2008, 2009) and Boes et al. (2007) among others. Implementing POLS begins by deriving $\left\{\mu_{j}\right\}_{j=0}^{J}$ values of a standard normal associated with the cumulative frequencies of the $J$ different categories of the dependent variable, with $\mu_{0}=-\infty, \mu_{J}=\infty$. Then the expectation of a standard normally distributed variable is taken for an interval between any two adjacent values. Thus if the true unobserved continuous variable for individual $i$ at time $t$ is $L S_{i t}^{*}$ where the observed is $L \mathrm{~S}_{i t}=j$ if $\mu_{j-1}<L \mathrm{~S}_{i t}^{*}<\mu_{j}$ for $j=1, \ldots, J$, then the conditional expectation of the latent variable is given by:

$$
L \ddot{S}_{i t}=E\left(L S_{i t}^{*} \mid \mu_{j-1}<L S_{i t}^{*}<\mu_{j}\right)=\frac{n\left(\mu_{j-1}\right)-n\left(\mu_{j}\right)}{N\left(\mu_{j}\right)-N\left(\mu_{j-1}\right)}
$$

where $n$ is the normal density and $N$ is the cumulative normal distribution. viii This approach allows the inclusion of individual fixed effects and the application of a linear estimator on the conditional expectations, which is assumed to be a function of observable characteristics

$$
L \ddot{S}_{i t}=\alpha X_{i t}+\beta y_{i t}+\gamma r_{i t}+v_{i}+\varepsilon_{i t}
$$

where $X$ includes age and age squared, years of completed education, household size (number of children and number of adults at home), and a set of dummy variables for gender, marital situation, employment status, immigrant condition, and health status. Year fixed effects and controls for the 16 German federal states are included as additional explanatory variables. The term $v_{i}$ represents the individual fixed effect and $\varepsilon_{i t}$ an iid error term.

In this paper we hypothesize that the effect that rank $r$ has on life satisfaction $(y)$ depends on the individual personality trait $p$. Since we assume that each personality facet is constant across time (see section 3.2.2), our estimation strategy is based on the premise that the vector of personality measures $p$ is

viii The stata routine used in the paper is available upon request. 
already included in the individual effect $v_{i}$. Since in the literature fixed effects are typically regarded as good controls for personality factors, our assumption, which mimics Boyce (2011), seems appropriate. We test for the existence of heterogeneous effects by interacting rank with the full vector of personality measures,

$$
L \ddot{S}_{i t}=\alpha X_{i t}+\beta y_{i t}+\gamma r_{i t}+\delta p_{i} \cdot r_{i t}+v_{i}+\varepsilon_{i t}
$$

A well determined coefficient on the personality-rank interaction terms would imply that the effect of individual rank on life satisfaction depends on individual's personality. Although a way to estimate equation (3) would be using an individual random effects model and include the personality measure as an independent variable, we preferred the current approach as one cannot safely assume orthogonality between an individual random effect and the explanatory variables. This is, we cannot assume that there is no correlation between, for example, intelligence or optimism and education or income.

\section{Results}

Table 3 reports the estimates. The first specification abstracts from rankpersonality interactions and is used to illustrate the income rank hypothesis: people gain utility from occupying a higher rank in the income distribution of their reference group. In the data, the average effect of rank income on life satisfaction amounts to $0.057(S D=0.017)$ and is significant at the $1 \%$ level. Using the coefficient of income as a reference $(0.131, S D=0.01)$, we calculate the trade-off between income and rank that maintains life satisfaction constant. We find that individuals would need a compensation of about $55 \%$ of their current income to move from the top (rank $=1$ ) to the bottom (rank $=0$ ) of the income distribution of their reference group $([\exp (0.057 / 0.131)-1] \times 100=$ $54.5 \%) .{ }^{i x}$

\footnotetext{
ix This is $[\exp (\gamma / \beta * \Delta r)-1] * 100$ in which "- 1 " and "*100" are added so as to obtain the result in percentage terms.
} 
As for the remaining covariates, the results are standard in the literature. Life satisfaction depends negatively on the number of adults at home, unemployment, singlehood and widowhood, and depends positively on employment and health. In the estimates, schooling is negatively related with life satisfaction, while the relationship between age and life satisfaction is ushaped with a minimum around 42 .

\subsection{The role of personality traits}

Next, we turn to the model with income-rank interactions. The results show a clear heterogeneity on the effect that rank has on life satisfaction. Although the rank coefficient remains virtually the same (0.052), 6 of the 8 personality measures show a statistically significant interaction with rank. Relative to the baseline effect of rank, people at the top of the extraversion, conscientious, external LOC, and negative reciprocity distribution are more rank sensitive. This is, their life satisfaction depends in greater manner to their position within the income distribution of the reference group. In contrast, individuals at the top of the openness-to-experiences and positive reciprocity distribution are less influenced by the rank they occupy in the income distribution. The interaction between rank and neuroticism and agreeableness is not statistically significant.

Using the results in Table 3, we can also calculate the trade-off between income and rank for different personality profiles. Table 4 summarizes these trade-offs for the different personality groups, using a 1-decile increase in rank as a reference. The second row transforms this equivalence into euros per month using the sample average household income. In addition, Table 4 includes, for all these estimates, the $95 \%$ confidence interval ${ }^{x}$. If we do not take personality differences into account, the income variation needed to compensate a 1-decile

\footnotetext{
$x$ The equivalent income measure is a ratio of two distinct covariates. Therefore, we need to take into account the standard deviation of such a ratio in order to compute the confidence interval. This is done by using the "nonlinear combinations of estimators" option in STATA, which yields first and second moments of nonlinear combinations of the different covariates.
} 
increase in rank is $4.46 \%$ which, for the sample average household income, amounts to $€ 114.6$ a month. This trade-off however varies depending on individuals' personality. For example, the corresponding figure is $€ 201.3$ or $7.84 \%$ for someone scoring one standard deviation above the average conscientiousness score. These numbers are very similar for those one standard deviation above the average of the extraversion $(6.27 \%)$, external LOC $(6.96 \%)$, and negative reciprocity $(6.07 \%)$ distribution. In contrast, and despite the interactions with rank were statistically significant, the trade-offs are not statistically significant for those one standard deviation above the openness-toexperiences and positive reciprocity distribution. This can be seen by inspection of the confidence intervals, which include the null value.

To sum up, the results are supportive of the prominent role of some personality features as a mediating force on the importance of relative income for life satisfaction. In other words, the results indicate that there are important differences across personality profiles.

An important question that arises is whether our findings on the importance of rank across personality profiles are in line with laboratory research in the field of psychology. Since the existing evidence is very scarce, comparison with our results must be taken with caution. As described earlier in the paper, the existing literature seems to indicate that conscientious individuals tend to value wealth accumulation (Ameriks et al., 2003), set themselves higher goals and care more about achieving them (Barrick et al., 1993; DeNeve and Cooper, 1998). It is likely that such a predisposition enlarges the importance of income comparisons for own reported life satisfaction, which is in line with the results presented in Table 3 of the paper. Our results however are not consistent in reference to neuroticism. While we do not find any statistically significant interaction between neuroticism and rank, the psychological literature fins neurotic people respond more sensitively to social comparisons, regardless whether they are downwards or upwards (Van der Zee et al., 1998), and individuals with low self-esteem, a related aspect of neuroticism, are more sensitive to comparisons both improving more their mood after comparing with 
worse-off others and responding more negatively after comparing with better-off others (Wheeler and Miyake, 1992; Aspinwall and Taylor, 1993). The extent to which one finds social comparisons inspiring or threatening depends on whether one finds a sense of control over the dimension under evaluation (Lockwood, 2002). Consistent with this view, we find that individuals at the top of the external locus of control are more sensitive to the rank they occupy than those at the average of the distribution. The available evidence for reciprocity is very scarce and does not explicitly relate to individuals' social comparisons. Also in line with the literature, in Table 3 we find that individuals at the top of the extraversion distribution are more sensitive (Derryberry and Reed, 1994).

\section{Conclusions}

This paper uses economic data from a large scale household survey to document the importance of personality traits to shape the importance that income rank has for individual satisfaction. Previous research in psychology, confined to laboratory or case studies, pointed to important personality effects in the response to social comparisons. The results of this paper, based on fixed effects estimates from the 2000-2013 waves of the German Socio-economic Panel and three different sets of personality measures are also suggestive of relevant differences across personality groups. We have found consistent evidence that the importance of income rank for individuals' reported life satisfaction varies significantly across individuals endowed with different personality traits.

A first implication of our findings regards the design of economic models. In words of Clark et al. (2008a) "taking relative income seriously is an important step toward greater behavioral realism in Economics, such that our models and empirical analysis move closer to how real people feel and behave". At the theoretical level, the distinction between absolute and relative formulations of utility has proven a useful concept to rationalize a large set of unexplained phenomena in a variety of fields, including consumption, savings, growth, and financial regularities. Acknowledging the extent of individual heterogeneity surrounding relative effects would prove fruitful to bring closer the theory to data and, most probably, to account for yet unexplained phenomena. As a second 
implication, welfare analysis should take into account the diverging importance of income externalities, for example, when designing optimal income taxation or defining poverty. The poverty literature has explicitly argued that relative concerns matter for individuals and some researchers have consequently defended that we should base the poverty line on relative rather than absolute consumption. Although in practice taking personality differences into account for relative poverty measures would be very difficult, our results warn that imposing a common benchmark might be misleading. This concern also applies to the welfare analysis of deprivation and social exclusion promoted within the Europe 2020 Strategy. Finally, and to the extent that individuals behave so as to improve their life satisfaction (Heffetz et al., 2012), the importance of income rank for individuals' life satisfaction will partly drive individuals' behavior in several life domains. Therefore, understanding the heterogeneity of preferences over relative income will help us to understand individuals' behavior in the markets. For example, status motives are an important determinant of labor supply and of amount of effort at work (Neumark and Postlewaite, 1998). Our results suggest that individuals endowed with different personality traits may respond very differently to relative income concerns. A next natural step would be to test these hypotheses using labor market data.

This paper contributes to the literature by corroborating the importance of income comparisons in Germany and most important by identifying an important source of heterogeneity. Our estimates identify certain personality profiles that tend to be more responsive to the social context and in concrete to the position they occupy within the income distribution of their reference group. These individuals will be much less responsive to general economic growth if equally distributed but they may be more responsive to job environments. Earlier findings in the literature show that some personality profiles are correlated with larger happiness reports (Boyce, 2010) and that personality also shapes the marginal utility of income (Boyce and Wood, 2011). Our results are consistent with these findings. Understanding the relationship between income comparisons, satisfaction, and personality identifies an important dimension in 
defining the heterogeneity in individuals' sensitiveness and therefore reactions to others' income. 


\section{Appendix}

The 15 BFI-S items are:

I see myself as someone who: (i) worries a lot, (ii) gets nervous easily, (iii) is relaxed, handles stress well, (iv) is communicative, talkative, (v) is outgoing, sociable, (vi) is reserved, (vii) is original, comes up with new ideas, (viii) values artistic experiences, (ix) has an active imagination, (x) is sometimes somewhat rude to others, (xi) has a forgiving nature, (xii) is considerate and kind to others, (xiii) does a thorough job, (xiv) does things effectively and efficiently, and (xv) tends to be lazy.

The first three items aim at capturing neuroticism. The second set relates to extraversion, followed by openness to experience, agreeableness, and the last 3 items relate to conscientiousness. Respondents can cast their answers on a 1 to 7 scale, where 1 stands for "does not apply to me at all" and 7 for "applies to me perfectly". Some items are reversely scored, i.e., a higher score negatively correlates with the dimension under evaluation. The measure used in the regression analysis for each of the five personality traits is an average across the three items. Therefore the personality measures used in the empirical analysis can range from 1 to 7 as well, even though we standardize this score in the regression stage of the paper.

The external LOC items are:

(i) haven't achieved what I deserve, (ii) what you achieve depends on luck, (iii) others make the crucial decisions in my life, (iv) possibilities are defined by social conditions, ( $v$ ) abilities are more important than effort, and (vi) little control over my life.

Respondents are asked to answer each item on a 1 to 7 scale, where 1 stands for "disagree completely" and 7 for "agree completely". A high score indicates that individuals have an external Locus of control. This is they feel that their life is largely driven by external factors such as luck and social conditions. 
The positive reciprocity items are:

(i) if someone does me a favour, I am prepared to return it, (ii) I go out of my way to help somebody who has been kind to me before, and (iii) I am ready to undergo personal costs to help somebody who helped me before.

The negative reciprocity items are:

(i) if I suffer a serious wrong, I will take revenge as soon as possible, no matter what the cost, (ii) if somebody puts me in a difficult position, I will do the same to him/her, and (iii) if somebody offends me, I will offend him/her back.

As in the other measures, the respondents can cast their response for each of these items on a 1 to 7 scale. The proxy measures used in the empirical analysis are the two averages over the three items. These averages are standardized in the regression stage of the paper. 


\section{References}

Akay, A. \& P. Martinsson (2012). Positional Concerns through the Life Cycle: Evidence from Subjective Well-Being Data and Survey Experiments. IZA Discussion Paper 6342.

Almlund, M., A.L. Duckworth, J.J. Heckman \& T.D. Kautz, (2011). Personality Psychology and Economics. NBER Working Papers, 16822, National Bureau of Economic Research, Inc.

Ameriks, J., A. Caplin, \& J. Leahy (2003). Wealth accumulation and the propensity to plan. Quarterly Journal of Economics, 118, 1007-1047.

Aspinwall, L. G. \& S.E. Taylor (1993). Effects of social comparison direction, threat, and self-esteem on affect, self-evaluation, and expected success, Journal of Personality and Social Psychology, 64, 708-722.

Barrick, M., M. Mount, M. \& J. Strauss (1993). Conscientiousness and performance of sales representatives - test of the mediating effects of goal setting. Journal of Applied Psychology, 78, 715-722.

Beach, S. R. and A. Tesser (2000). Self-evaluation maintenance and evolution: Some speculative notes. In J. Suls and L. Wheeler (Eds.), Handbook of social comparisons. Mahwah, NJ: Lawrence Erlbaum.

Blanchflower \& A. Oswald (2004). Well-being over time in Britain and the USA. Journal of Public Economics, 88, 1359-1386.

Boes, S., M. Lipp, and R. Winkelmann (2007). Money illusion under test. Economics Letters, 94: 332-337.

Borghans, L., A. Duckworth, J. Heckman \& B. ter Weel (2008). The economics and psychology of personality traits, Journal of Human Resources 43(4), 9721059.

Boyce, C. J. (2010). Understanding fixed effects in human well-being, Journal of Economic Psychology, 31, 1-16

Boyce, C., G. Brown \& S. Moore (2010a). Money and happiness: rank of income, not income, affects life satisfaction. Psychological Science, 21(4), 471-475.

Boyce, C., A.M. Wood \& G. Brown (2010b). The dark side of conscientiousness: Conscientious people experience greater drops in life satisfaction following unemployment. Journal of Research in Personality, 44, 535-539.

Boyce, C. J., \& A.M. Wood (2011). Personality and the marginal utility of income: Personality interacts with increases in household income to determine life satisfaction. Journal of Economic Behavior \& Organization, 78, 183-191.

Boyce, C.J., A.M. Wood, and N. Powdthavee (2013). Is Personality Fixed? Personality Changes as Much as "Variable" Economic Factors and More Strongly Predicts Changes to Life Satisfaction. Social Indicators Research, 111: 287-305.Brown, G., J. Gardner \& A. Oswald (2008). Does Wage Rank Affect Employees' Well-being?, Industrial Relations, 47(3), 355-389.

Cacioppo, J., L.C. Hawkley, A. Kalil, M.E. Hughes, L. Waite \& R.A. Thisted (2008). Happiness and the Invisible Threads of Social Connection: The Chicago Health, Aging and Social Relations Study. In The Science of Subjective Well-Being, M. Eid and R.J. Larsen (Eds.), The Guilford Press, New York.

Caliendo, M., D. Cobb-Clark \& A. Uhlendorff (2014a). Locus of Control and Job Search Strategies. Review of Economics and Statistics, 97(1): 88-103. 
Caliendo, M., F. Fossen, and A.S. Kritikos (2014b). Personality characteristics and the Decision to become and stay self-Employed, Small Business Economics, forthcoming.

Caporale, G.M., Y. Georgellis \& Y.P. Yin (2009). Income and happiness across Europe: Do reference values matter? Journal of Economic Psychology, 30, 425.

Clark, A. (2001). What really matters in a job? Hedonic measurement using quit data, Labour Economics, 8: 223-242.

Clark, A.E., P. Frijters \& M. Shields (2008a). Relative income, happiness and utility: an explanation for the Easterlin paradox and other puzzles. Journal of Economic Literature, 46, 95-144.

Clark, A.E., E. Diener, Y. Georgellis \& R.E. Lucas (2008b). Lags And Leads in Life Satisfaction: a Test of the Baseline Hypothesis. Economic Journal, 118(529), 222-243.

Clark, A., N. Kristensen \& N. Westergaard-Nielsen (2009a). Economic Satisfaction and Income Rank in Small Neighbourhoods. Journal of the European Economic Association, 7(2-3), 519-527.

Clark, A., N. Kristensen \& N. Westergaard-Nielsen (2009b). Job Satisfaction and Co-Worker Wages: Status or Signal? Economic Journal, 119(536), 430-447.

Clark, A. \& C. Senik (2010). Who Compares to Whom? The Anatomy of Income Comparisons in Europe. Economic Journal, 120(544), 573-594.

Cobb-Clark, D. A. \& Schurer, S. (2012). The stability of big-five personality traits. Economics Letters, Elsevier, 115(1), 11-15.

Costa, P.T., \& R.R McCrae (1992). NEO PI-R. Professional manual. Odessa, FL: Psychological Assessment Resources, Inc.

Costa, P. T. \& R.R McCrae (2002). Looking backward: Changes in the mean levels of personality traits from 80 to 12 . In D. Cervone and W. Mischel (Eds.), Advances in personality science, New York: Guilford Press, 219-237.

Danner, D., D.A. Snowdon \& W.V. Friesen (2001). Positive emotions in early life and longevity: findings from the nun study, Journal of Personality and Social Psychology, 80, 804-813.

DeNeve, K. \& H. Cooper, H. (1998). The happy personality: A meta-analysis of 137 personality traits and subjective well-being. Psychological Bulletin, 124, 197- 229.

Derryberry, D. and M. A. Reed (1994). Temperament and attention: Orienting toward and away from positive and negative signals. Journal of Personality and Social Psychology, 66, 1128-1139.

Di Tella, R., R. MacCulloch, \& A. Oswald (2003). The macroeconomics of happiness, Review of Economics and Statistics, 85(4): 809-827.

Dittmann, J. \& J. Goebel, (2010). Your House, Your Car, Your Education: The Socioeconomic Situation of the Neighborhood and its Impact on Life Satisfaction in Germany. Social Indicators Research, 96, 497-513.

Falk, A. \& M. Knell (2004). Choosing the Joneses: Endogenous Goals and Reference Standards. Scandinavian Journal of Economics, 106(3), 417-435.

Ferrer-i-Carbonell, A. \& P. Frijters (2004). How important is methodology for the estimates of the determinants of happiness? The Economic Journal, 114, 641659.

Ferrer-i-Carbonell, A. (2005). Income and Well-being: An Empirical Analysis of the Comparison. Income Effect. Journal of Public Economics, 89, 997-1019.

Ferrer-i-Carbonell, A. (2013). Happiness Economics. SERIES, 4: 335-60 
FitzRoy, F., M. Nolan, \& M.F. Steinhardt (2014). Testing the tunnel effect; comparison, age and happiness in the UL and German panels. IZA Journal of European Labor Studies, 3-24

Frey, B. \& A. Stutzer (2002). What can economists learn from happiness research? Journal of Economic Literature, 40(2), 402-435.

Frick, J.R., S.P. Jenkins, D.R. Lillard, O. Lipps, and M. Wooden. 2007. The CrossNational Equivalent File (CNEF) and its Member Country Household Panel Studies. Schmollers Jahrbuch 127, 4: 627-654.

García, S. M., A. Tor, M. H. Bazerman and D. T. Miller (2005). Profit versus disadvantageous inequality: The impact of self-categorization. Journal of Behavioral Decision Making, 18, 187-198.

Gibbons, F. X., C. P. Benbow and M. Gerrard (1994), From top dog to bottom half: Social comparison strategies in response to poor performance, Journal of Personality and Social Psychology, 67, 638-652.

Guven, G., C. Senik and H. Stichnoth (2012). You can't be happier than your wife. Happiness gaps and divorce. Journal of Economic Behavior and Organization, 82: 110-130.

Ham, R., P.N. Junankar \& R. Wells (2009). Occupational Choice: Personality Matters. IZA Discussion Paper No. 4105.

Hampson S.E., L.R. Goldberg, T.M. Vogt and J.P Dubanoski, 2006. Forty years on: teachers' assessments of children's personality traits predict self-reported health behaviors and outcomes at midlife. Health Psycholgy: 25(1):57-64.

Hahn, E., Gottschling, J. and Spinath, F. (2012), Short measurements of personality - Validity and reliability of the GSOEP Big Five Inventory (BFI-S), Journal of Research in Personality (46)3, 355-359.

Heckman, J.J., J.E. Humphries, and T. Kautz (editors), 2014. The Myth of Achievement Tests: The GED and the Role of Character in American Life. Chicago University Press, Chicago, US.

Heffetz, O., D.J. Benjamin, M.S. Kimball, \& A. Rees-Jones (2012). What Do You Think Would Make You Happier? What Do You Think You Would Choose? American Economic Review, 102(5), 2083-2110.

Heineck, G. \& S. Anger (2010). The returns to cognitive abilities and personality traits in Germany. Labour Economics, 17(3), 535-546.

Helliwell, J.F. \& Huang, H. (2010). How's the job? Well-being and social capital in the workplace. Industrial and Labor Relations Review, 63(2), 205-227.

Herzberg, P.Y and; Brähler, E. (2006), Assessing the Big-Five personality domains via short forms: A cautionary note and a proposal, European Journal of Psychological Assessment, 22(3), 139-148.

Hirschman, A.O. (1973), The changing tolerance for income inequality in the course of economic development, with a mathematical appendix by Michael Rothschild. Quarterly Journal of Economics, 87: 544-566

Kandler, C., W. Bleidorn, R. Riemann, A. Angleitner \& F. Spinath (2012). Life events as environmental states and genetic traits and the role of personality: $A$ longitudinal twin study, Behavior Genetics, 42(1), 57-72.

Lang, F.R., D. John, I. Lüdtke, J. Schupp abd G.G. Wagner. 2011. Short assessment of the Big Five: robust across survey methods except telephone interviewing. Behavior Research Methods 43, 2: 548-567.

Larsen, R. J. and T. Ketelaar (1991). Personality and susceptibility to positive and negative emotional states. Journal of Personality and Social Psychology, $61,132-140$. 
Lockwood, P. (2002), Could It Happen to You? Predicting the Impact of Downward Comparisons on the Self. Journal of Personality and Social Psychology, 82(3), 343-358.

Luttmer, E. (2005). Neighbours as negatives: Relative earnings and well-being. Quarterly Journal of Economics, 120, 963-1002.

Lyubomirsky, S., \& Ross, L. (1997). Hedonic consequences of social comparison: A contrast of happy and unhappy people. Journal of Personality and Social Psychology, 73, 1141-1157.

Lyubomirsky, S. \& K.L. Tucker (1998). Implications of individual differences in subjective happiness for perceiving, interpreting and thinking about life events. Motivation and emotion, 22, 155-186.

Lyubomirsky, S., K.L. Tucker \& F. Kasri (2001). Responses to hedonically conflicting social comparisons: Comparing happy and unhappy people. European Journal of Social Psychology, 31, 511-535.

McBride, M. (2001). Relative income effects on subjective well-being in the cross-section. Journal of Economic Behavior and Organization, 45, 251-278.

McGue, M., Bacon, S. and Lykken, D.T. (1993). Personality Stability and Change in Early Adulthood: A Behavioral Genetic Analysis. Developmental Psychology, 29(1), 96-109.

Mohanty, M. S. (2010). Effects of Positive Attitude and Optimism on Employment: Evidence from the US data. Journal of Socio-Economics, 39, 258-270.

Mueller, G. \& E. Plug (2006). Estimating the Effect of Personality on Male-Female Earnings. Industrial and Labor Relations Review, 60(1), 3-22.

Neumark, D. \& A. Postlewaite (1998). Relative income concerns and the rise in married women's employment. Journal of Public Economics, 70, 157-183.

Oswald, A. \& S. Wu (2010). Objective Confirmation of Subjective Measures of Human Well-being: Evidence from the USA. Science 327(5965), 576-579.

Piatek, R. and P. Pinger, 2015. Maintaining (Locus of) Control? Data Combination for the Identification and Inference of Factor Structure Models, Journal of Applied Econometrics, forthcoming.

Powdthavee, N. (2009). How important is rank to individual perception of economic standing? A within-community analysis. Journal of Economic Inequality, 7(3), 225-248.

Proto, E. and A. Rustichini, (2011). Life satisfaction, income and personality theory. In: IZA Workshop: Sources of Welfare and Well-Being, IZA, Bonn. (Unpublished).

Rammstedt, B. and John, O. P. (2007), Measuring personality in one minute or less: A 10-item short version of the Big Five Inventory in English and German, Journal of Research in Personality 41(1), 203-212.

Roberts, B. W. \& W.F. DelVecchio (2000). The rank-order consistency of personality from childhood to old age: A quantitative review of longitudinal studies. Psychological Bulletin, 126, 3-25.

Roberts B.W., A. Caspi and T.E. Moffitt (2001). The kids are alright: growth and stability in personality development from adolescence to adulthood. Journal of Personality and Social Psychology, 81: 670-683

Roberts, B. W., K. Walton \& W. Viechtbauer (2006). Patterns of mean-level change in personality traits across the life course: A meta-analysis of longitudinal studies. Psychological Bulletin, 132, 1-25. 
Rotter, J.B. (1966), Generalized expectancies of internal versus external control of reinforcements. Psychological Monographs, 80: 609.

Seidlitz, L., R.S. Wyer \& E. Diener (1997). Cognitive correlates of subjective well-being: The processing of valenced life events by happy and unhappy persons. Journal of Research in Personality, 31, 240-256.

Semykina, A \& S. Linz. (2007). Gender differences in personality and earnings: Evidence from Russia. Journal of Economic Psychology 28(3): 387-410.

Senik, C. (2004). When information dominates comparison: Learning from Russian subjective panel data. Journal of Public Economics, 88(9-10), 20992133.

Senik, C. (2005). What Can we Learn from Subjective Data? The Case of Income and Well-Being. Journal of Economic Surveys, 19(1), 43-63.

Senik, C. (2009). Direct evidence on income comparisons and their welfare effects. Journal of Economic Behavior and Organization, 72(1), 408-424.

Soto, C., O. John, S. Gosling \& J.Potter (2011). Age differences in personality traits from 10 to 65: Big Five domains and facets in a large cross-sectional sample. Journal of Personality and Social Psychology, 100, 330-348.

Specht, J., B. Egloff \& S.C. Schmukle (2011). The benefits of believing in chance or fate: External locus of control as a protective factor for coping with the death of a spouse. Social Psychological and Personality Science, 2, 132-137.

Stevenson, B. and J. Wolfers (2008). Economic growth and subjective wellbeing: reassessing the Easterlin Paradox. Brookings Papers on Economic Activity, Spring 2008.

Stevenson, B. and J. Wolfers (2009). The Paradox of Declining Female Happiness. American Economic Journal: Economic Policy, 1: 190-225.

Swallow, S. R. and N. A. Kuiper (1992). Mild Depression and Frequency of Social Comparison Behavior. Journal of Social and Clinical Psychology, 11(2), 167180.Uysal, S. D. \& W. Pohlmeier (2011). Unemployment duration and personality, Journal of Economic Psychology, 32(6), 980-992.

Thimme, J. (2016): Intertemporal Substitution in Consumption: A Literature Review, Journal of Economic Surveys, DOI: 10.1111/joes.12142.

van Praag, B.M.S. \& A. Ferrer-i-Carbonell (2008). Happiness Quantified: A Satisfaction Calculus Approach, Oxford University Press. Revised edition.

Van der Zee, K., F. Oldersma, B. Buunk \& D. Bos (1998). Social comparison preferences among cancer patients as related to neuroticism and social comparison orientations. Journal of Personality and Social Psycology, 75, 801810.

Wheeler, L. \& K. Miyake (1992). Social comparison in everyday life. Journal of Personality and Social Psychology, 62, 760-773.

Wagner, G.G., J.R. Frick, and J. Schupp. 2007. The German Socio-Economic Panel Study (SOEP) - Scope, Evolution and Enhancements. Schmollers Jahrbuch 127, 1: 139-169.

Wood, J. V. \& K. Van der Zee (1997). Social comparisons among cancer patients: Under what conditions are comparisons upward and downward? In B. P. Buunk and F. X. Gibbons (Eds.), Health, coping, and well-being: Perspectives from social comparison theory (pp. 299-328). Hillsdale, NJ: Erlbaum. 
Tables and figures

Table 1. Summary statistics - Socioeconomic characteristics

\begin{tabular}{lrr}
\hline \hline & Mean & SD \\
\hline Life satisfaction & 6.973 & 1.770 \\
Household income & 2782.000 & 1913.000 \\
Age & 49.880 & 16.940 \\
Woman & 0.522 & 0.500 \\
Years education & 12.210 & 2.695 \\
No. of adults & 2.155 & 0.834 \\
No. of children & 0.497 & 0.876 \\
Employed & 0.622 & 0.485 \\
Unemployed & 0.066 & 0.249 \\
Inactive & 0.312 & 0.463 \\
Married & 0.662 & 0.473 \\
Single & 0.197 & 0.397 \\
Divorced & 0.076 & 0.265 \\
Widow & 0.066 & 0.247 \\
Badhealth & 0.172 & 0.378 \\
East Germany & 0.252 & 0.434 \\
Foreigner & 0.106 & 0.307 \\
\hline \hline
\end{tabular}

Table 2. Summary statistics - Personality traits

\begin{tabular}{lrr}
\hline \hline & Mean & SD \\
\hline Neuroticism & 3.872 & 1.215 \\
Extraversion & 4.796 & 1.123 \\
Openness-to-exp eriences & 4.463 & 1.196 \\
Agreeableness & 5.395 & 0.971 \\
Conscientiousness & 5.887 & 0.914 \\
External LOC & 3.687 & 0.940 \\
Positive recip rocity & 5.860 & 0.902 \\
Negative reciprocity & 3.068 & 1.434 \\
\hline \hline
\end{tabular}


Table 3. Rank and personality, FE - German SOEP 2000-2013

\begin{tabular}{|c|c|c|c|c|}
\hline & Coeff. & t-ratio & Coeff. & t-ratio \\
\hline Household income & 0.131 w w w the & 12.580 & $0.135^{\text {sol }}$ & 12.870 \\
\hline Rank & 0.057 w & 3.340 & $0.052^{\text {wopk }}$ & 3.040 \\
\hline \multicolumn{5}{|l|}{ Rank interactions with } \\
\hline Neuroticism & & & 0.009 & 0.830 \\
\hline Extraversion & & & $0.030^{\text {*ow }}$ & 2.710 \\
\hline Openness-to-experiences & & & -0.039 w & -3.640 \\
\hline Agreeableness & & & 0.015 & 1.230 \\
\hline Conscientiousness & & & 0.050 *ook & 4.490 \\
\hline External LOC & & & $0.039 *$ & 4.680 \\
\hline Positive reciprocity & & & -0.026 & -2.810 \\
\hline Negative reciprocity & & & $0.027 *$ & 2.480 \\
\hline Ln (Age) & -0.834 & -4.230 & -0.861 * & -4.370 \\
\hline $\operatorname{Ln}\left(\mathrm{Age}^{2}\right)$ & $0.111 *$ & 3.520 & 0.114 & 3.620 \\
\hline Ln (Years of schooling) & $-0.128 * *$ & -2.450 & $-0.126^{* *}$ & -2.410 \\
\hline Ln (No. of adults) & -0.089 w west & -7.350 & -0.088 & -7.220 \\
\hline Ln (No. of children) & 0.000 & 0.000 & 0.001 & 0.150 \\
\hline Employed & 0.018 & 2.680 & $0.018 * *$ & 2.610 \\
\hline Unemployed & 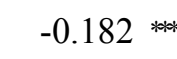 & -21.670 & $-0.181 *$ & -21.540 \\
\hline Single & -0.067 w w w & -5.740 & -0.069 * & -5.890 \\
\hline Divorced & 0.063 & 5.390 & 0.065 * & 5.540 \\
\hline Widow & -0.110 & -7.020 & -0.106 & -6.640 \\
\hline Badhealth & -0.412 하 & -79.480 & -0.412 & -79.440 \\
\hline R-squared & 0.149 & & 0.132 & \\
\hline No. of obs. & 223,805 & & 223,805 & \\
\hline
\end{tabular}

Notes to Table 3: i) * denotes significance at the $10 \%$ level, $* *$ denotes significance at the $5 \%$ level, *** denotes significance at the $1 \%$ level; ii) Year fixed effects and controls for the 16 German federal states are included as additional regressors. 
Table 4. The rank-household income equivalence scale, by personality groups

\begin{tabular}{lcccc}
\hline \hline & Average & & $95 \%$ confidence interval \\
\hline Rank & $4.46 \%$ & {[} & $1.23 \% ;$ & $7.80 \%]$ \\
Rank with & $114.6 €$ & {[} & $31.6 € ;$ & $200.16 €]$ \\
Neuroticism & $4.61 \%$ & {[} & $1.06 \% ;$ & $8.28 \%]$ \\
& $118.3 €$ & {[} & $27.1 € ;$ & $212.7 €]$ \\
Extraversion & $6.27 \%$ & {[} & $2.43 \% ;$ & $10.24 \%]$ \\
& $161.0 €$ & {[} & $62.5 € ;$ & $262.9 €]$ \\
Openness-to-experiences & $0.96 \%$ & {$[-2.11 \% ;$} & $4.12 \%]$ \\
& $24.6 €$ & {$[-54.1 € ;$} & $105.8 €]$ \\
Agreeableness & $5.07 \%$ & {[} & $1.35 \% ;$ & $8.93 \%]$ \\
& $130.2 €$ & {[} & $34.6 € ;$ & $229.3 €]$ \\
Conscientiousness & $7.84 \%$ & {[} & $3.85 \% ;$ & $11.99 \%]$ \\
& $201.3 €$ & {[} & $98.8 € ;$ & $307.8 €]$ \\
External LOC & $6.96 \%$ & {[} & $3.20 \% ;$ & $10.85 \%]$ \\
& $178.6 €$ & {[} & $82.2 € ;$ & $278.5 €]$ \\
Positive reciprocity & $1.98 \%$ & {[} & $-1.07 \% ;$ & $5.12 \%]$ \\
& $50.8 €$ & {[} & $-27.6 € ;$ & $131.5 €]$ \\
Negative reciprocity & $6.07 \%$ & {[} & $2.30 \% ;$ & $9.97 \%]$ \\
& $155.8 €$ & {[} & $59.0 € ;$ & $256.0 €]$ \\
\hline \hline
\end{tabular}


Figure 1.Distribution of personality traits

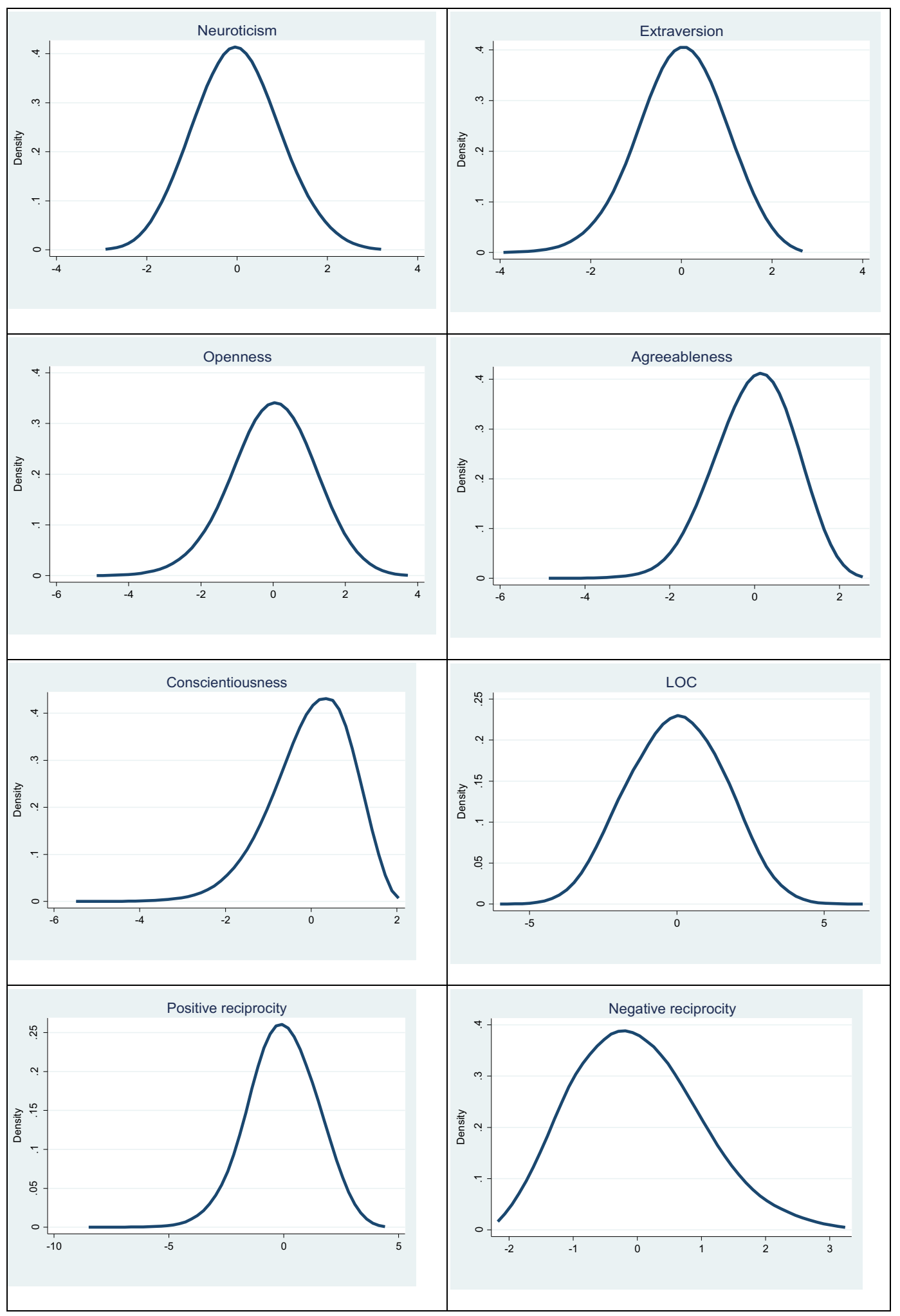

